\title{
TEATROS SALMANTINOS Y ACTIVIDAD MUSICAL EN EL PRIMER CUARTO DEL S.XX A TRAVÉS DE LA PRENSA LOCAL
}

\author{
Salamanca's theater and musical activity in the first quarter of twentieth century
} through the local press.

Francisco José Álvarez García (Universidad Pontificia de Salamanca)

E-mail: fjalvarezga@upsa.es

Fecha de recepción: 18-II-2011

Fecha de aceptación: 23-II-2011

Resumen: Los teatros de comienzos del S. XX son unos de los focos principales en los que se condensa la actividad músico-artística de pequeñas y grandes ciudades españolas. Salamanca no podía ser menos y de la mano de los teatros "Liceo", "Bretón" y "Moderno" recoge una actividad musical muy rica puesta de manifiesto a través de Zarzuelas, Conciertos, Teatro lírico, Tunas etc., que harán de la ciudad del Tormes centro del panorama musical de la provincia y alrededores hasta prácticamente la Segunda República

Palabras clave: Salamanca, Teatro Liceo, Teatro Bretón, Teatro Moderno, Actividad Musical, Zarzuela.

ABSTRACT: The theaters at the beginning of twentieth century are one of the main focuses in which condenses the musician-artistic activity of small and large Spanish cities. Salamanca could not be less and in the three capitals theaters "Liceo", "Bretón" and "Moderno" we find a very rich musical activity like Zarzuelas, Concerts, Lyric Theatre, Tunas, etc., which will make to Salamanca the most important center of the music scene in the province until almost the Second Spanish Republic

Keywords: Salamanca, Liceo Theater, Bretón Theater, Modern Theater, Musical Activity, Spanish Operetta. 


\section{INTRODUCCIÓN}

Salamanca, del mismo modo que otros núcleos urbanos de comienzos del S. XX, posee sus escenarios naturales que van a desempeñar la función de entablar un diálogo artístico con el público que acude, respondiendo a su llamada. Los teatros son, junto con los cafés y salones de variedades, los máximos representantes dentro de este género en la ciudad, y su estudio, es de vital importancia para conocer el ambiente musical de una localidad concreta.

En la capital del Tormes, contamos, en 1900 con dos únicos teatros, el Liceo, con actividad desde el último tercio del S.XIX, y el teatro Bretón, recién bautizado como tal, pero con actividad constatada desde mucho tiempo atrás (concretamente desde finales del S. XVIII., bajo los auspicios del Hospital de la Santísima Trinidad).

En 1909, surge un tercer representante que pronto se convertirá en uno de los escenarios más representativos del panorama musical salmantino, al acoger multitud de representaciones líricas y conciertos, sobre todo de la mano de la naciente también, Sociedad Filarmónica Salmantina y también por complementar, a modo de comodín, las opciones en cuanto al género lírico se refiere: El salón Moderno.

Tras esta contextualización genérica, sirvan los siguientes epígrafes para estudiar las diferentes manifestaciones musicales en los tres teatros de la ciudad conociendo, con más detalle, la historia de cada edificio, función, clase social vinculada y sobre todo actividad artística desempeñada.

\section{TEATRO DEL LICEO}

ElLiceo es, sin duda, uno delos emblemas culturales más representativos en Salamanca desde su construcción, en 1862. Levantado sobre las ruinas del convento de San Antonio el Real del S.XVIII., (desaparecido durante la guerra de la independencia), concretamente donde se situaba el claustro y la sacristía de la propia iglesia del convento, la construcción mantiene, desde sus orígenes, la tipología de teatro italiano que, tras su última restauración, en 2004 , recuperó de nuevo.

Su ubicación en la actual plaza del Liceo (antes calle del Doctor Riesco y, en el S.XIX, calle de la calzada de Toro), muy cerca del centro neurálgico de la ciudad (la Plaza Mayor se sitúa a menos de 100 metros del edificio), convierten al teatro en aglutinante cultural y social, donde confluyen diferentes tipologías de experiencias socio-artísticas, desde fiestas populares y bailes de sociedad, hasta manifestaciones artístico-teatrales de todo tipo, pasando por múltiples formas de expresión musical, (como conciertos, teatro lírico, etc.), conviviendo además, a partir de comienzos del S.XX, con cine, espectáculos de revista, y otros.

Durante el primer cuarto del S. XX, el Liceo es, junto con el Teatro Bretón (y a partir de Marzo de 1909 también junto al Salón Moderno), el 
único espacio cultural popular, al margen de las decenas de instituciones y sociedades privadas tan de moda a finales del S.XIX, y comienzos del S.XX, casi todas de índole obrero o conformadas en torno a la tipología "Círculo" o "Casino".

Dentro de este pequeño grupo de teatros públicos, el Liceo es, además, el único vinculado a las clases sociales más altas, equiparándose, en determinadas ocasiones, a la exclusividad de los círculos privados más prestigiosos, (como el Casino de Salamanca, Círculo del Pasaje o Círculo Mercantil e Industrial) y diferenciándose, de este modo, del Bretón o Moderno, de connotaciones mucho más populares y vinculadas a una clase social media y media-baja.

“(...) El Liceo distinguióse por lo distinguido de la concurrencia y el orden que reinó; Bretón y el Artístico por el gentío que en ambos habia y por algunas reyertas que, por fortuna, no tuvieron importancia. (...)"'.

El teatro, desde sus orígenes planteado al modo italiano, estaba decorado en el techo con pinturas alegóricas al drama y la comedia, así como a músicos y dramaturgos nacionales. Sin duda, el aspecto del mismo, lo convertía en uno de los espacios públicos más imponentes de la ciudad.

"(...) Parece que lo estamos viendo como estaba entonces, con su hermoso telón de boca, pintado artísticamente. Las pinturas del techo eran alegorias del teatro y retratos de músicos y dramaturgos españoles célebres. Estas pinturas tenian sabor, le daban un carácter a la sala. pero se conoce que aquello "ya no se llevaba" y desaparecieron por completo (...)'n.

Contaba con unas 550 localidades, distribuidas entre butacas, palcos, tribunas y gallinero (también denominado "paraíso"). La ocupación de las mismas, con sutiles diferencias según el tipo de espectáculo, estaba determinado por el género y la categoría social del espectador, reservándose los palcos y plateas para las familias más pudientes, las butacas generales delanteras y centrales para señoras y señoritas de clase media-alta, las butacas traseras para caballeros de la misma clase y el gallinero para el sector masculino de clase media y, sobre todo, los estudiantes.

"(...) [los jóvenes] que actualmente se ubican principalmente en las butacas, entonces lo hacian en el "Paraíso" o "Gallinero", como vulgarmente se llamaba a la entrada general, en el último piso. Su presupuesto no daba para más. Aun siendo bijos de familia acomodada, es decir, estudiantes, aquella era corrientemente su localidad, mientras sus novias o pretendidas, ocupaban las localidades bajas. En elpatio de butacas se veian señoras y señoritas de la clase media, y en palcos y plateas (éstas ya no existen), las más "eficopetadas" (...)"”.

1 “Los bailes", El Adelanto -Salamanca-, 3 de Febrero de 1901; B.G.U.S.

2 ANSEDE, C. R.: "De la Salamanca de ayer: usos, costumbres, recuerdos..." Salamanca: Diputación de Salamanca, 1969. Págs. 13 y 14.

3 ANSEDE, C. R.: "De la Salamanca de ayer: usos, costumbres, recuerdos...” Salamanca: 
El teatro, aunque vinculado a un condominio constituido por representantes del propio Ayuntamiento, la Diputación Provincial y otras instituciones de índole nacional (siendo, por lo tanto, de administración pública), estaba controlado por un grupo de empresarios que lo gestionaban, tras el correspondiente arriendo, de forma particular.

Así, cada tres o cinco años, salían a la luz, en concurso abierto, por pliegos y condiciones cerradas, (a modo de subasta a la alta), los derechos de explotación del teatro, disponiendo de los mismos, durante el periodo referido, el mejor postor (o postores).

"El Domingo 8 de Mayo, a las doce del mediodía, tendrá lugar la subasta para el arrendamiento, por el tiempo de cinco años, del elegante Teatro del Liceo de Salamanca por pliegos cerrados y bajo las condiciones que están de manifiesto en la conserjería de dicho teatro, adonde se remitirán los pliegos de subasta. Si no hubiese postores para este arrendamiento, a la misma hora y el mismo dia, se procederá al arriendo del mismo teatro por el tiempo de $1^{\circ}$ de Junio a 30 de Septiembre, admitiéndose proposiciones para tal objeto, reservándose el condominio de admitir o no las proposiciones para este arrendamiento".

Los empresarios (o empresario particular), acordaban un precio con el condominio, (que solía revisarse anualmente), repartiéndose la diferencia entre lo recaudado cada temporada y lo aportado en el contrato, (comprometiéndose con el Consistorio a mantener algunas fechas $y$ actividades ineludibles, como el teatro en ferias, los bailes de carnaval, etc.)

“(...) Se presentaron seis proposiciones, aceptando el condominio la subscrita por don Joaquín del Estal, tomando el coliseo por cinco años, a razón de unas diez mil quinientas pesetas anuales"'.

La gestión del teatro (por lo tanto, en el fondo, privada), buscaba, (como no podía ser de otra forma entre socios-empresarios), la mayor rentabilidad del local, contratando, los referidos empresarios, a su vez, los espectáculos que con una mejor relación calidad-precio, llenaran las butacas, palcos y gallinero, reportándose así los mejores beneficios.

El precio medio de una localidad, (dependiendo claro está, del tipo y género de la función), solía rondarlos tres reales/peseta para la entrada general, y las 5/7 pesetas para los palcos y plateas, abaratándose, sensiblemente, al ofrecerse la posibilidad del abono, (normalmente durante la visita de alguna compañía de zarzuela o también con motivo de la celebración de algún ciclo de conciertos).

Diputación de Salamanca, 1969. Págs. 13 y 14.

4 "Arriendo del Teatro del Liceo", El Adelanto -Salamanca-, 4 de Mayo de 1904; B.G.U.S.

5 “Crónica Local y Provincial”, El Adelanto -Salamanca-, 16 de Mayo de 1904; B.G.U.S. 
“(...) El precio de la entrada lo mismo de señora que de caballero será una peseta $y$ los palcos y plateas cinco pesetas por abono y siete a diario (...)".6.

Esta condición lucrativa y privada determinó, en gran medida y como es lógico, la tipología y desarrollo cultural del teatro en la época a estudio, consignándose, en muy contadas ocasiones, por ejemplo, (al margen del entorno de la Sociedad Filarmónica Salmantina, totalmente independiente del condominio y de los gestores particulares), conciertos de grandes orquestas o recitales musicales que pudiéramos calificar de "primera división", al ser mucho más cara su contratación y conllevar entradas con precios casi astronómicos, incluso para la clase social media-alta, muy alejados de la realidad cotidiana salmantina.

En cuanto a la tipología de espectáculo ofrecido en el teatro, éste era realmente diverso, aunque muy marcado por el ciclo y calendario estacional, siendo bastante fácil determinar la actividad del Liceo, (sobre todo en representativas fechas vinculadas a tradiciones y celebraciones populares), echando una rápida ojeada al calendario.

Señalemos las actividades más significativas por periodos y épocas:

a.) Octubre-Noviembre: Comienzo de la temporada (paralelamente al curso escolar, quizá derivado de la importancia de Salamanca como ciudad universitaria). Las primeras compañías de teatro o teatro lírico acuden, contratadas por los empresarios de turno, ofreciendo las primeras funciones, pudiéndose mantener en escena, aproximadamente, de tres semanas a un mes. Con el anuncio de la misma, se impone la publicación del elenco completo de la formación.

"El sábado 11 del corriente debutará en este lindo coliseo la gran compañia de zarzuela del género chico bajo la dirección del primer actor don Salvador Orozco y cuya lista publicamos a continuación (...)".

También son corrientes los conciertos y recitales de variada tipología y, algunos años, la celebración de bailes de otoño, (al modo de los encontrados en salones y locales mucho más pequeños, pero de gran importancia en el ambiente musical salmantino)

Coincidiendo con la festividad de Todos los Santos, de permanecer sobre las tablas una compañía dramática (o incluso lírica), era corriente la representación del clásico "Don Juan Tenorio".

"(...) A las siete y media de la noche: El grandioso drama de don José Zorrilla titulado "Don Juan Tenorio" (...)"s.

6 “Crónica Local y Provincial”, El Adelanto -Salamanca-, 2 de Febrero de 1900; B.G.U.S.

7 “Teatro del Liceo", El Adelanto -Salamanca-, 6 de Noviembre de 1905; B.G.U.S.

8 “Teatro del Liceo", El Adelanto -Salamanca-, 1 de Noviembre de 1907; B.G.U.S. 
b.) Diciembre-Enero: Prosigue la temporada teatral. Normalmente encontramos actividad de esta índole de Octubre a Noviembre, o de Diciembre a Enero, siendo extraño consignar, cuatro meses continuos durante la temporada de invierno, ni siquiera alternando compañías.

"Como días de fiesta, el sábado y domingo las entradas han sido muy buenas en ambos teatros, y los artistas han conseguido distraer al público y hacerse aplaudir (...)" ".

c.) Febrero: Se suspenden prácticamente las representaciones por parte de las compañías y dan comienzo los conciertos y recitales de la tunas locales y foráneas, así como la temporada de bailes de carnaval, empezando por el clásico de "Candelas" y terminando, dos semanas después con el de "Piñata".

“(...) Conforme estaba anunciado, anoche tuvo lugar en este espacioso y favorecido coliseo, el tradicional y popular baile de Candelas, el cual, vióse tan animado y concurrido, como todos los años. En el salón se congregó lo más escogido y selecto de nuestra juventud. (...) ${ }^{\text {'ro }}$.

d.) Marzo-Agosto: Temporada de verano. Casi todos los años con poca o ninguna actividad teatral profesional (sobre todo los meses propios de la estación estival).

La mayor parte de los espectáculos ofrecidos, vienen de la mano de festivales de variada tipología, pertenecientes a diferentes sociedades e instituciones privadas; conciertos y recitales, también de índole particular, normalmente en favor, socorro, o beneficio de los propios organizadores; funciones de variedades, contratadas esporádicamente por los gestores arrendatarios del salón; teatro o zarzuela, pero casi siempre de connotación amateur, vinculado a la misma tipología de institución benéfica o sociedad, antes mencionada, y otros.

"El próximo día 15, a las 8:45 de la noche, celebrará la Sociedad "el Teatro" en este coliseo, la función correspondiente al mes de marzo. Se pondrá primeramente en escena la obra "Entre doctores". Después la bella señorita Luisa Pequeño y el maestro Goyenechea ejecutarán al piano y al armonium respectivamente, el Scherzo en si menor de Chopin, y la rapsodia número 11 de Listz....."'11.

e.) Septiembre: Temporada de Ferias: Los empresarios ofrecen la mejor compañía que pueden permitirse (teatro o zarzuela, alternando con el Bretón), pues la entrada, como saben por experiencia, está garantizada, no sólo por el público local, sino, en gran parte, por la afluencia de forasteros que visitan Salamanca y que gustan del teatro una vez abandonan la plaza de toros, (tan animada en la coincidente y tradicional semana grande taurina).

9 "Los teatros", El Adelanto -Salamanca-, 3 de Enero de 1910; B.G.U.S.

10 “Los bailes”, El Adelanto -Salamanca-, 3 de Febrero de 1908; B.G.U.S.

11 "Teatro del Liceo", El Adelanto -Salamanca-, 12 de Marzo de 1908; B.G.U.S. 
"Esta noche tendrá lugar el debut de la compañia que ha de actuar en este lindo coliseo, con la zarquela en tres actos "Jugar con Fuego". A las OCHO Y MEDIA en punto. Entrada general UNA peseta"12.

Evidentemente esta clasificación temporal a vuelapluma, cuenta con innumerables excepciones en el calendario, pero puede servirnos para hacernos una idea del corriente de la tradición local, en cuanto a la distribución de espectáculos.

Aun constituyendo un entramado realmente diverso y complejo, podemos intentar establecer también, una clasificación genérica, atendiendo ahora a la tipología de los diferentes espectáculos, reseñados por la prensa, celebrados en el Liceo, de 1900 a 1910, con algún tipo de connotación musical:

a.) Conciertos y recitales instrumentales de agrupaciones pequeñas.

La mayor parte de los mismos, son ejecutados por músicos locales y aficionados, vinculados a las propias sociedades e instituciones organizadoras, aunque, de vez en cuando, la empresa arrendadora del teatro, contrata a músicos y agrupaciones foráneas de relevancia, como en la siguiente noticia de El Adelanto, referente a la actuación instrumental de las hermanas valencianas Adelina y Lucía Domingo que, al violín y al piano respectivamente, amenizaron algunos días de Enero, el coliseo de la calle del Doctor Riesco.

"Agotaríamos todos los elogios de rigor en casos tales, para reseñar el concierto que anoche tuvo lugar en referido coliseo, y no conseguiriamos consignar con exactitud ni la inimitable maestría que demostraron en él las señoritas Domingo, ni el entusiasmo, tan grande como merecido con el que el público pagó su artística labor"'3. orquesta.

b.) Conciertos y recitales instrumentales de grandes agrupaciones y

Todavía con menos frecuencia en el calendario del Liceo, encontramos actividad de medianas orquestas o agrupaciones instrumentales de cierta entidad, normalmente ligadas a un acontecimiento social especial, como la visita de algún ministro, miembro de la Casa Real, un concierto de Tomás Bretón o Felipe Espino, etc. Este tipo de recitales, además de constituir, de alguna forma, uno de los antecedentes más importantes para el nacimiento, al final de la década a estudio, de la Sociedad Filarmónica Salmantina, eran muy apreciados por el público, convirtiendo la asistencia a los mismos en un verdadero acontecimiento social.

12 “Teatro del Liceo", El Adelanto -Salamanca-, 8 de Septiembre de 1901; B.G.U.S.

13 “Teatro del Liceo", El Adelanto -Salamanca-, 5 de Enero de 1900; B.G.U.S. 
"El segundo y último de los conciertos celebrados anoche en el Liceo fue como el anterior, un entusiasta triunfo para nuestro paisano Espino y para sus compañeros los componentes del sexteto (...)"

c.) Compañías de zarzuela de género grande o chico.

Muy en la moda de finales del S. XIX y principios del S. XX, las compañías denominadas, coloquialmente, "de provincias", acudían, normalmente en las temporadas antes apuntadas, con un programa lírico sorprendentemente novedoso, estrenando zarzuelas con muy pocas semanas de diferencia de las presentaciones oficiales en la capital y perfectamente coordinadas y autorizadas por la incipiente Sociedad General de Autores.

Estas zarzuelas (en ocasiones pequeñas piezas líricas teatrales, caprichos musicales e incluso adaptaciones de ópera), eran llevadas a término por los componentes de la compañía, a excepción de la parte instrumental que, aunque dirigida normalmente por un maestro concertador del propio elenco, estaba conformada por músicos "mercenarios", pertenecientes a una orquesta del propio teatro, y completados, en ocasiones, por algún primer violín o pianista de la propia compañía.

Este tipo de agrupaciones improvisadas y muy cambiantes, estaban formadas por músicos locales, casi todos profesores particulares, miembros de agrupaciones salmantinas o simplemente aficionados, muchas veces pertenecientes a otras bandas locales, con un importante nivel instrumental.

Con su participación en la "orquesta del Liceo" (por ejemplo), completaban unos ingresos que, en la mayor parte de los casos, no eran suficientes para las precarias circunstancias generales de la Salamanca de comienzos de siglo.

“(...) Bajo la batuta del joven maestro nuestra orquesta parecía otra; sonaba mejor, matizaba bien, daba sus justos valores a las notas y hasta el apacible señor Haedo y el popular "Trinchán", se permitían sus filigranas: el uno en el clarinete y el otro en la trompa. (....)'

d.) Tuna Escolar y espectáculos diversos de ámbito instrumental estudiantil.

Acercándose las fechas del carnaval y, sobre todo las temporadas en las que las diferentes formaciones de la Tuna Escolar Salmantina, postulaban para realizar una salida a tierras lusitanas, eran muy corrientes las celebraciones populares de conciertos de la estudiantina, que sirvieran de base para sufragar los propios gastos de la excursión.

14 "El concierto de anoche", El Adelanto -Salamanca-, 6 de Abril de 1905; B.G.U.S.

15 “Teatro del Liceo”, El Adelanto -Salamanca-, 13 de Mayo de 1909; B.G.U.S. 
También era común encontrar, por las mismas fechas, a agrupaciones, también escolares, de visita en Salamanca, convirtiéndose así los meses de Enero a Marzo, en una de las temporadas más afines al concierto universitario.

e.) Festivales benéficos, orfeones, inauguraciones de curso, sociedades teatrales locales y otras representaciones populares artístico musicales.

Siendo el Teatro del Liceo el espacio más relevante en el campo de la representación artística de la ciudad, desde muy pronto, se convirtió en el mejor escaparate para mostrar los avances que, desde diferentes tipos de sociedades y agrupaciones, se iban alcanzando.

De esta forma, por ejemplo, cuando el incipiente Orfeón Salmantino en Marzo de 1906, al regresar de Portugal, decide mostrar el espectáculo ofrecido en Oporto, no encuentra mejor contexto que el propio teatro, garantizándose, a su vez, a través de la suculenta entrada prevista, unos importantes beneficios.

De igual modo sociedades benéficas, compañías teatrales y de zarzuela amateurs (como "El Teatro" o "Bohemios"), reconocen, en el galante coliseo, un espacio idóneo para presentar sus últimos logros, a la vez que garantizar la consideración y buena entrada de lo mejorcito de la sociedad salmantina.

f.) Acontecimientos musicales especiales.

Por la misma razón apuntada en el punto anterior, junto con el Bretón, el teatro del Liceo tiene el honor de albergar algunos de los acontecimientos especiales más importantes, de índole musical, acaecidos en Salamanca a lo largo de la década a estudio. Así, la serie de conciertos "Espino" con su aplaudido sexteto, o el estreno en 1911 de "Alma Charra", del popular maestro, fueron verificados en tan insigne coliseo.

\section{TEATRO BRETÓN}

El Teatro Bretón, aun siendo con diferencia el local de espectáculos más antiguo de Salamanca es, en importancia y actividad durante el primer cuarto del S. XX, el menos relevante en cuanto a participación músico-teatral se refiere, incluso por detrás, en muchos aspectos del, desde su inauguración en 1909, Salón Moderno.

Desde mediados del S. XVIII., existía en el lugar que ocupa el coliseo (calle de San Justo, junto a una de las grandes arterias de la ciudad: la Gran Vía) un corral de comedias y luego teatro llamado "del Hospital". El teatro estaba vinculado al Hospital de la Santísima Trinidad ayudando, con sus ingresos, al sostenimiento del mismo.

En 1898 adquirió su nombre actual en honor al insigne músico Tomás Bretón que, casualmente, había nacido en las cercanías y era, por entonces, el artista oriundo más importante de la región.

En cuanto a la configuración arquitectónica del espacio actual, Tomás 
Cafraga, fue el encargado del proyecto original del teatro de 1846, levantado sobre la ubicación del referido corral del S. XVIII. De la posterior reforma del mismo, a finales del S. XIX, se encargó Cecilio González Domingo.

Las principales modificaciones al proyecto de Tomás Cafraga, fueron la construcción de un muro de cierre del solar, por la calle San Justo y por el chaflán, que lo enlazó con la antigua fachada, (que se encuentra en el lado del patio de comedias) y la colocación de una nueva puerta principal, que se abría en un muro fajeado y se cerraba con un arco segmentado.

En el primer piso, sobre el eje de la entrada, Cecilio González Domingo abrió una ventana-balcón, siendo su recerco y los sillares resaltados en las esquinas, los únicos elementos que animaban la pared. Un frontón, con un motivo decorativo en su vértice, constituyó el remate superior hasta su última reforma de importancia, en 1940.

El resto de las reformas, se realizaron en 1919, con el recrecimiento de la fachada como añadido más significativo, y la citada de 1940, con variantes internas, que conllevaron una modificación general, con un importante cambio en la decoración del espacio central y la boca del teatro.

Posteriormente se añadieron varias salas de cine en la zona de la Plaza de San Román, que en un primer momento se conocieron como "Cine Patio de Comedias" y más tarde, junto a todo el edificio, se convirtieron en el propio "Cine Bretón".

En 2004 fue clausurado y cerrado, encontrándose en vía muerta a fecha actual (incluso parcialmente derruido), planteándose, desde la municipalidad y un sector privado, la posibilidad reconvertir el espacio en apartamentos y viviendas de alquiler, proyecto por ahora paralizado y muy cuestionado por un grupo importante de la población.

$\mathrm{Al}$ margen de esta visión general, es importante señalar que el teatro no ha mantenido una actividad medianamente continuada, como el referido Liceo, durante los primeros 25 años del S. XX, sino que, muchas veces, a causa de las innumerables pequeñas reformas y, en la mayor parte de las ocasiones, por problemas derivados de la gestión del mismo (también siguiendo la tipología de condominio público con arriendos privados, al modo de su teatro hermano), ha tenido sus puertas cerradas, dejando al propio Liceo, (hasta la aparición del Salón Moderno, en 1909) en solitario, como único teatro en Salamanca.

En cuanto a su función social, como ya hemos adelantado en el capítulo anterior, el teatro es, sin duda, el salón más popular de la clase media. De manera un tanto coloquial, podríamos denominarlo como "el teatro del pueblo".

En él, se celebran bailes públicos, conciertos y presentaciones teatrales, zarzuela, etc., del mismo modo que en el estudiado Liceo, pero, con precios 
un poco más ajustados y, en general, con una merma significativa en la calidad de los espectáculos ofrecidos.

Esta disminución en la calidad de la actividad, en ocasiones, y de manera sorprendente, es compensada con la designación del teatro como sede de acontecimientos (musicales y de otras tipologías), de gran relevancia en la ciudad, que, durante el periodo comprendido entre 1900 y 1925, llevaron espectáculos de las connotaciones citadas, con más frecuencia incluso, a las tablas del Bretón que a las del Liceo.

Esto es debido a que parte de la administración del teatro, (al igual que la estudiada para el Liceo), estaba controlada por la propia municipalidad y aunque arrendaba a distintos empresarios, por un tiempo determinado, la gestión del mismo, imponía una serie de condiciones a su propio arbitrio, que le permitían determinar ciertos espectáculos sobre sus tablas, modificando, considerablemente, el tipo de asistente al local, (que de manera puntual podía encontrarse entre las clases más humildes).

Alfonso XIII (por ejemplo), asistió a diferentes espectáculos en el mismo, durante su estancia en Salamanca, en Septiembre de 1904.

También intervenciones tan importantes como la presentación en Salamanca de los populares "Cantos Charros” de Dámaso Ledesma, los famosos conciertos que el maestro Tomás Bretón verificó de la mano de la Sociedad Filarmónica de Madrid, durante las ferias de 1907, o los propios actos relacionados con la visita de la infanta Paz de Borbón, en Abril de 1909, se celebraron en el Teatro Bretón.

\section{SALÓN MODERNO}

El salón Moderno, teatro Moderno o "la bombonera de don Cayo" (como también era cariñosamente conocido), Siendo de los tres teatros consignados en el presente artículo, el último en ser levantado (en Marzo de 1909), es también el único, que no ha llegado a nuestros días, habiendo sido derribado en 1965, (a esperas de conocer el destino final del propio Teatro Bretón).

"El público lo vio con simpatía, y pronto lo empezaron a llamar "La Bombonera de Don Cayo"; como llamaban en Madrid al bello teatro de D. Cándido Lara (La bombonera de don Cándido) (....)"16.

Tanto el edificio como la propia concepción del teatro en sí, (incluyendo la gestión artística), surge de un prestigioso jurista salmantino, don Cayo Alvarado, gran amante del teatro y la zarzuela que, viendo un próspero negocio en el subarriendo de un local teatral a las, cada vez más crecientes y prolíficas, compañías cómicas, dramáticas y de zarzuela denominadas "de provincias", decide, animado, por otra parte, por el reciente auge del

16 ANSEDE, C.R.: "De la Salamanca de ayer: usos, costumbres, recuerdos..." Salamanca: Diputación de Salamanca, 1969. Pág. 46. 
cinematógrafo a comienzos del nuevo siglo, levantar un nuevo salón, en unos terrenos de su propiedad, de reciente adquisición, en la Cuesta del Carmen, entre las actuales calles de Bordadores e Íscar Peyra, (esta última inexistente a comienzos de siglo).

"Un día don Cayo se acercó a la taquilla de nuestro Teatro Liceo para adquirir una localidad, pues quería ver la bonita comedia que representaban aquella noche, "Entre doctores" de Vital Aza, si no recuerdo mal, Pero don Cayo se quedó con las ganas de verla, porque no consiguió localidad, y entonces dijo: "Si, eh. Pues ahora voy a hacer un teatro para mi solo, es decir, para que nunca me falte localidad". Y siendo un hombre decidido, como lo pensó, lo hizo. Derribó unas casas viejas de la Cuesta del Carmen y levantó el teatro (...)'"r'.

Las obras fueron ejecutadas a un ritmo vertiginoso, no llevando, según las crónicas del momento, ni tan siquiera un año desde las primeras tareas de derribo de las deterioradas viviendas sitas en los terrenos de don Cayo, hasta la culminación de la empresa.

La construcción del edificio fue encomendada al arquitecto catalán Carlos Grasset y los maestros de obra fueron los salmantinos Genaro García y Vicente Andrés, amigos particulares del jurista. Parece ser que durante el levantamiento del teatro, tomaron parte más de 50 obreros, una cifra nada despreciable para los proyectos urbanísticos del momento.

“(...) El salón moderno ha sido construido en poco menos de un año. Las obras comenzaron a primeros de julio de 1908 y ya es un hecho que para el 11 de abril próximo va a estar por completo terminado. El proyecto se debe al reputado arquitecto don Carlos Grasset y han dirigido las obras, muy acertadamente por cierto, nuestros queridos amigos los maestros señores don Genaro García y don Vicente Andrés. En las obras han tomado parte unos 50 obreros (...)"'s8.

Ilustración I: Ubicación del Salón Moderno en Salamanca, de 1909 a 1965. (Google Maps.)

El resultado final, a ojos de la prensa del momento, fue magnífico, otorgando al humilde salón, (a pesar de sus pequeñas dimensiones, al lado de los otros dos representantes salmantinos), grandes calificativos, haciendo hincapié en la sencillez de sus formas, sus extraordinarios acabados, la buena gestión y empresa de su promotor, y el confort general que el teatro emanaba.

"(...) De perfecto gusto, de gran sencillez en la construcción, el nuevo teatro de don Cayo es una deliciosa "bombonera" como ya se ha dicho en llamarle, en la que no falta

17 ANSEDE, C.R.: "De la Salamanca de ayer: usos, costumbres, recuerdos..." Salamanca: Diputación de Salamanca, 1969. Pág. 46.

18 “Informaciones locales", El Adelanto -Salamanca-, 24 de Marzo de 1909; B.G.U.S. 
nada: confort, comodidades, higiene, ventilación, todo lo que necesita un coliseo para que el público lo visite y... La Cierva no decrete su clausura. (...)" ${ }^{19}$.

“(...) La portada causó una gran impresión en el público. Era linda de veras y artística, rematada con una bonita figura alegórica. La sala, de larga dimensión, tenía más de 400 butacas de patio y un piso con gradas y delantera, para otros tantos espectadores. El escenario no era pequeño; tenía suficiente tamaño para las decoraciones y para que se movieran bien en él los actores. No queremos decir que fuera un hermoso teatro, pero su capacidad estaba bien para la Salamanca de entonces (.... '’20.

El coste total de la obra, según los descendientes del señor Alvarado, entrevistados por Cándido Ansede ${ }^{21}$, pudo haber ascendido hasta las 150.000 pesetas, una cantidad desorbitada para la época. El Adelanto y el resto de la prensa local, sin embargo, sitúan la cifra final en torno a las, tampoco nada despreciables, 100.000 pesetas (600 euros) ${ }^{22}$.

"(...) Se calcula que la construcción del salón moderno ha costado con la compra de solares unas 100.000 Ptas. Y esta cifra no parecerá exagerada a nadie que visite el salón moderno y se detenga a examinar el lujo y lo acabado de la obra. (...)"233.

Coincidiendo con su inauguración, a través de la prensa local, encontramos una descripción muy precisa del exterior e interior del teatro, obteniendo datos acerca del número de localidades hábiles, la constitución de su fachada, su distribución interior, la decoración de la sala mayor y del resto de las estancias, capacidad y situación de los camerinos, instalaciones generales (calefacción, luz, etc.), servicios, responsables y artistas de la decoración y de las citadas instalaciones, etc.

“(...) El salón moderno tiene una muy considerable cabida de personas. Pasadas las puertas de entrada que dicho sea de paso son de un gusto exquisito, así como la artística fachada, hay una sala de espera y mide $13 \mathrm{~m}$. de lado y la cabina para el cine. El patio de butacas es amplio y elegante y hay de 300 a 320 butacas, elegantes y de moderno sistema. En la pared medianera que separa la sala de espera del patio de butacas hay además de la cabina para los cinematógrafos, dos palcos, con los que no se puede contar, pues se destinan para las autoridades y para la empresa. En el piso principal, único que tiene el nuevo coliseo, están las localidades que se denominan "delanteras" y "entrada

19 “Informaciones locales", El Adelanto -Salamanca-, 24 de Marzo de 1909; B.G.U.S.

20 ANSEDE, C. R.: “De la Salamanca de ayer: usos, costumbres, recuerdos...”. Salamanca: Diputación de Salamanca, 1969. Pág. 46.

21 ANSEDE, C. R.: “De la Salamanca de ayer: usos, costumbres, recuerdos...”. Salamanca: Diputación de Salamanca, 1969. Pág. 46.

22 Salvando las correspondientes distancias para este tipo de comparaciones, podríamos estar hablando, en la actualidad, de un gasto de unos 12 millones de Euros, cantidad prácticamente inalcanzable para un promotor particular.

23 "Informaciones locales", El Adelanto -Salamanca-, 24 de Marzo de 1909; B.G.U.S. 
general", con lujosas barandillas y cómodos asientos. Habrá 80 delanteras y 220 entradas generales. El escenario mide $8 \times 8$, y dispone de telones metálicos y de agua, además del de boca. En el piso principaly junto a una salita de espera, hay otro salón destinado para café restaurante y cervecería, con amplios balcones y lujoso mostrador. Los cuartos de los artistas, que son seis, han sido construidos en el foso del escenario. El teatro cuenta con ocho puertas de salida: dos principales, cuatro laterales y dos por el escenario. El servicio de retretes es admirable, estando en las mejores condiciones de salubridad. El decorado del teatro, es muy artístico y acredita una vez más al conocido maestro don Manuel Ramírez: La Instalación de la calefacción, por tubos, ha sido hecha por don Ramón Nuño, y las decoraciones para el teatro por el aventajado discipulo de Muriel, señor Olaya. Don Antonio Ferreira ba dirigido las instalaciones eléctricas, cuyos aparatos son tan sencillos como bonitos y elegantes. (.... $)^{24}$.

“(...) La obra en conjunto es una preciosidad y respecto a la solidery seguridades nada hay que decir, habiendo dirigido la construcción del edificio maestros tan competentes como Genaro García y Vicente Andrés (... $)^{25}$.

Curiosamente y, al contrario de lo que se ha publicado con anterioridad ${ }^{26}$, la inauguración del teatro se produjo con un concierto de la Sociedad Filarmónica Salmantina, sociedad musical que, como veremos, alquiló el salón en varias ocasiones para celebrar allí sus recitales de temporada pues, al parecer, la acústica de la sala debía ser bastante buena, (entre otras circunstancias, por sus diminutas proporciones).

El concierto para piano y chelo, (noveno, dentro de la segunda temporada de la sociedad), fue ofrecido por Monsieur Voged, profesor de piano del Conservatorio de Rotterdam y Monsieur Von Sterdaël, prestigioso chelista y compositor del Conservatorio de la Haya.

"El nuevo teatro Salón Moderno. La inauguración. El nuevo teatro salón moderno, que nuestro querido amigo don Cayo Alvarado ba construido en la cuesta del Carmen, será inaugurado boy... familiarmente. Y decimos familiarmente, porque la inauguración del nuevo coliseo será sólo para los socios de la filarmónica salmantina, cuyo concierto tendrá lugar esta noche. (....)'27.

Cayo Alvarado, su promotor, trasladó el molde administrativo del Liceo y Bretón a su "bombonera", subarrendando el teatro, por temporadas, normalmente anuales, a diferentes empresarios, que se encargaban, a su vez, de establecer contacto con las propias compañías de zarzuela, dramáticas, de espectáculos de variedades, cinematógrafos, agrupaciones variadas, etc., que, finalmente, acudían a ofrecer su función.

24 “Informaciones locales", El Adelanto -Salamanca-, 24 de Marzo de 1909; B.G.U.S.

25 “Informaciones locales", El Adelanto -Salamanca-, 24 de Marzo de 1909; B.G.U.S.

26 Según Cándido Ansede en su "La Salamanca de Ayer...", fue la compañía madrileña "Lope de Vega" la encargada de inaugurarlo.

27 “Informaciones locales”, El Adelanto -Salamanca-, 24 de Marzo de 1909; B.G.U.S. 
Don Cayo se reservaba, a la vez, el derecho de establecer, de manera unipersonal, determinados espectáculos y arriendos, encargándose en todo momento de la gestión de su teatro, (sobre todo durante su primera campaña).

"(...) Los espectáculos que en el salón moderno han de exbibirse, serán cultos, honestos y nuevos. (...) El teatro ha sido subarrendado a una empresa tan acreditada como la del coliseo Imperial de Madrid. La citada empresa de la cual es Presidente nuestro compañero en la prensa el periodista madrileño señor García Plaza, se propone dar a conocer en dicho salón un espectáculo honesto, agradable y culto, del mismo género cultivado en los teatros de la Comedia y Lara de Madrid. (...)’’28.

Prueba de que la gestión del jurista salmantino era más que buena, la constituye el hecho de la permanencia de las compañías, sobre todo de zarzuela, de paso por Salamanca, en el Moderno, multiplicándose por dos (y en ocasiones por tres), el tiempo medio de estancia de las mismas, en comparación con los otros dos teatros de la capital del Tormes. Hasta ópera llegó a representarse en las tablas de la "bombonera".

“(...) Yo puedo asegurar que pasaron por su escenario buenas compañias de drama, comedia y zarzuela y que les iba muy buen lo demuestra que se estaban dos y tres meses. Pero todavía me falta decir que, en este escenario, vimos hasta óperas. Recuerdo haber visto en él "Cavalleria Rusticana" y "El Gato Montés" (...)”2'.

Una de las diferencias principales del nuevo salón con respecto a los otros dos teatros ya existentes, era el precio de las localidades, que, en raras ocasiones, excedía de los tres reales, independientemente del tipo de espectáculo ofrecido.

La popularidad de los precios garantizó, sobre todo los primeros años de existencia del mismo, una entrada fabulosa y pingües ganancias a su administrador.

“(...) Los precios de salón moderno serán tan reducidos que la butaca no excederá de 60 céntimos. (...) ${ }^{330}$.

Pero tras 12 o 15 años de existencia apoyado en el negocio teatral y lírico, la abrumadora realidad cinematográfica, logró relegar al noble género a un segundo plano, convirtiéndose, desde antes de la guerra, en un salón de cine, propiamente, (con muy contadas excepciones, a lo largo del año).

“(...) Tras de todas aquellas temporadas, de bastantes años de arte teatral, aquel telón se bajó definitivamente para darpaso al cine, que se vio también muy concurrido siempre (...."31.

28 "Informaciones locales", El Adelanto -Salamanca-, 24 de Marzo de 1909; B.G.U.S.

29 ANSEDE, C. R.: “De la Salamanca de ayer: usos, costumbres, recuerdos...”. Salamanca: Diputación de Salamanca, 1969. Pág. 46.

30 “Informaciones locales", El Adelanto -Salamanca-, 24 de Marzo de 1909; B.G.U.S.

31 ANSEDE, C. R.: “De la Salamanca de ayer: usos, costumbres, recuerdos...”. Salamanca: 
Inexorablemente y por causas relacionadas con la especulación inmobiliaria, el teatro fue derribado en la primavera de 1965, para construir, en su lugar, lujosas viviendas en el centro de la capital.

“(...) en Febrero de 1965 cerró sus puertas. A primeros de Mayo comenzó su derribo y a fin de Julio ya no existía nada de él. En su lugar creo que van a construir viviendas (...)'"32.

La actividad relacionada con el ambiente musical salmantino se circunscribió, en el Salón Moderno, dentro de tan sólo dos tipologías muy concretas aunque, a la vez, de una gran representatividad: la propia zarzuela, llevada a cabo por diferentes compañías de provincias que, lejos de lo que pueda parecer en una primera impresión, gozaron siempre de muy justa fama, desempeñando su labor más que dignamente, (estando, sin duda, a la altura de los elencos del Bretón, y cómo no del Liceo); y la actividad desarrollada por la Sociedad Filarmónica Salmantina en el contexto de sus conciertos que, gustando de la familiaridad del teatrito, de su acústica, de sus novedosas instalaciones y de su alto confort, fue elegido, en varias ocasiones por la junta directiva, para la celebración de sus recitales.

\section{Bibliografía}

ALIER, R./ AVIÑOA, X.: "El libro de la zarzuela". Ediciones Daimon. Barcelona, 1982.

ALVAREZ GARCÍA, F. J.: "La actividad musical en Salamanca a través de la prensa local. 1900-1910”. Tesis Doctoral. USAL: Departamento de Historia y Ciencias de la Música. Salamanca, 2009.

ANSEDE, C.R.: "De la Salamanca de ayer: usos, costumbres, recuerdos..." Salamanca: Diputación de Salamanca, 1969.

ARAUJO, F.: "La reina del Tormes: Guía histórica descriptiva de la ciudad de Salamanca". Biblioteca de la Caja de Ahorros y Monte de Piedad de Salamanca, 1984.

ARNAU, J/GÓMEZ, C. M. : "Historia de la zarzuela”. Editorial Zacosa, Madrid, 1979.

CARNERO, I.: "Diccionario de personajes, topónimos y demás nomenclaturas del callejero salmanticense". Salamanca. Diputación Provincial y Ayuntamiento de Salamanca. 1964.

CASARES RODICIO, E.: "Diccionario de la zarzuela, España e Hispanoamérica”. Madrid: Instituto Complutense de Ciencias Musicales, 2003.

Diputación de Salamanca, 1969. Pág. 47.

32 ANSEDE, C. R.: “De la Salamanca de ayer: usos, costumbres, recuerdos...”. Salamanca: Diputación de Salamanca, 1969. Pág. 45. 
CASARES RODICIO, E.: "La música española hasta 1939, o la restauración musical", Actas del Congreso Internacional "España en la Música de Occidente”, II, Madrid, Ministerio de Cultura, 1987.

CONESA. M.: “La Salamanca de los Gombau”. Junta de Castilla y León. Salamanca, 1996.

CORTÉS VÁZQUEZ, L.: "Presentación de una ciudad: Salamanca". Publicaciones de los cursos de verano de la Universidad de Salamanca, 1971.

FERNÁNDEZ GARCÍA, E.: "León y su vida escénica en la segunda mitad del S. XIX”. Tesis Doctoral. UNED. Departamento de Literatura Española y de Teoría de la Literatura. Madrid, 1997.

GARCÍA FRAILE, D.: "Salamanca en la Historia de la música española", capítulo XXI de "Salamanca, Geografía, Historia, Arte, Cultura", dirigida por Ángel Cabo y Alfonso Ortega. Ayuntamiento de Salamanca, Servicio de Publicaciones, Salamanca, 1986.

GARCÍA GARCÍA, J. M.: "Prensa y vida cotidiana en Salamanca (siglo XIX): Aproximación a la historia del periodismo salmantino". Universidad de Salamanca, Salamanca, 1990.

GARCÍA LABORDA, J. M.: "La Sociedad Filarmónica de Madrid. Contexto histórico y valoración del repertorio”. Universidad de Salamanca. Salamanca, 2006.

GUTIÉRREZ DE CEBALLOS, C.: "Salamanca a finales del S. XIX”. Publicaciones de la Diputación Provincial de Salamanca. 1997.

KENT, C.: "La Plaza Mayor de Salamanca. Historia fotográfica de un espacio público”. Salamanca: Salamanca 2005, Plaza Mayor de Europa, 2005.

KENT, C.: "El perfil de Salamanca”. Salamanca 2005, Plaza Mayor de Europa, 2005.

LINARES VALCÁRCEL, F.: “La vida escénica en Albacete. 19011923”. Tesis Doctoral. U.N.E.D: Departamento de Literatura Española, Facultad de Filología. Madrid, 1997.

MAILLO SALGADO, S.: "Felipe Espino, un músico posromántico y su entorno”. Salamanca: Anthema Ediciones, 1999.

MARTÍNEZ DEL RÍO. R.: "Historia de la Universidad de Salamanca". Ediciones Universidad de Salamanca. Salamanca, 2004.

RUIBAL OUTES, TOMÁS.: "La vida escénica en Pontevedra en la segunda mitad del siglo XIX”. Tesis Doctoral. U.N.E.D: Departamento de Literatura Española, Facultad de Filosofía y Letras. Madrid, 1997.

SAMANIEGO BONEU, M. "Publicaciones periódicas salmantinas, 1793-1936: Contribución al estudio de fuentes para la historia de Castilla- 
león". Departamento de Historia Contemporánea, Universidad de Salamanca, 1984.

SÁNCHEZ SÁNCHEZ, V:: "Tomás Bretón, un músico de la Restauración”. Madrid: Instituto Complutense de Ciencias Musicales, 2002.

TORIBIO ANDRÉS, E.: "Salamanca y sus alrededores, su pasado, su presente y su futuro". Talleres Tipográficos Cervantes, Salamanca, 1954.

VV. AA.: "La Zarzuela de cerca". Fundación Jacinto e Inocencio Guerrero, Colección Austral, Espasa Calpe, 1987. Madrid. Selección de estudios, realizada y presentada por Andrés Amorós.

VILLAR Y MACÍAS, M.: "Historia de Salamanca". Graficesa, Salamanca, 1975.

WEBBER, C: “The Zarzuela Companion”. Scarecrow Press, 2002. 